\title{
Transport Planning Challenges in Existing Urban Planning Process - Case of Vietnam Urban Planning
}

\author{
Vo Minh Phuc ${ }^{1}$, Vo Trong Cang ${ }^{2}$ \\ ${ }^{1}$ Sustainable Urban Development (SUD), Vietnamese German University, Ho Chi Minh City, Viet Nam \\ ${ }^{2}$ Faculty of Transportation Engineering, Ho Chi Minh City University of Technology, Ho Chi Minh City, Viet Nam
}

Email address:

vominh.phuc95@gmail.com (Vo M. Phuc), vtcang@hcmut.edu.vn (Vo T. Cang)

\section{To cite this article:}

Vo Minh Phuc, Vo Trong Cang. Transport Planning Challenges in Existing Urban Planning Process - Case of Vietnam Urban Planning. Landscape Architecture and Regional Planning. Vol. 4, No. 1, 2019, pp. 10-14. doi: 10.11648/j.larp.20190401.13

Received: December 21, 2018; Accepted: March 11, 2019; Published: March 25, 2019

\begin{abstract}
Urban planning is a technical and political process concerned with the development and design of land use and other problems, such as transportation, communications and its distribution networks. In Ho Chi Minh City case, the fastest developing city in Vietnam, the transportation problems have become worse and worse, recently. Even through received lots of concerns from Ho Chi Minh City government and notices from many different stakeholders, traffic jam and others traffic problem keep occur and increase-in-level in many new projects area of Ho Chi Minh City. In fact, there are several challenges for Vietnam urban planners to develop Ho Chi Minh City without exacerbated the current traffic situation. In scope of this article, some specific challenges in urban transportation planning, in Vietnamese urban planning process, would be identified, such as: Limitation in Traffic impact assessment, the limitation in analysis approach method for forecasting and reduction of traffic problem; and lack of communication and synchronous cooperation between departments and other agencies in municipalities. After research on these challenges in urban transportation planning in Vietnamese urban planning process, some related solutions will be research and proposed in future research articles.
\end{abstract}

Keywords: Transport, Urban Planning, Transport Impact Assessment (TIA), Spatial Planning, Land Use Structure, Inner-Urban Area Design

\section{Introduction}

Urban planning is a technical and political process concerned with the development and design of land use and the built environment, including air, water, and the infrastructure passing into and out of urban areas, such as transportation, communications, distribution networks [1].

The transport planning is a part of infrastructure planning. Depend on the scale of planning, the Environment Impact Assessment (EIA) need to be supported by the Strategic Environment Assessment (SEA) [2]. Beside that, the transport planning is conducted based on Transport Impact Assessment (TIA) and the criteria of spatial planning - land use structure - urban design [3].

In Vietnam, urbanization speed has increased significantly, especially in $\mathrm{Ha}$ Noi and Ho Chi Minh City cases since 2000s. The rapid increase in urban population has put high pressure on urban development, and caused lots of negative effects on urban residents and the future development.

Among several of negative affect, traffic jam is one of the most annoying phenomena.

Therefore, the traffic planning has become an important process of any urban planning projects. Even received lots of concerns, notices from many stakeholders, traffic jam still occur in many new projects, which are expected not to suffer from traffic jam, such as: Pham Van Dong Boulevard in Ho Chi Minh City or Nguyen Chi Thanh Street in Ha Noi. In order to solve the problem, the transport planning needs to be practiced with the wider and further vision. To reach that vision, several challenges need to be overcome. These challenges would be identified in this article and solutions would be proposed later, in future articles. 


\section{Urban Planning Process in Vietnam for Inner-Urban Area}

Urban planning is the complicated process, with several of smaller, detailed process, such as: site characteristic review and analysis; site zoning; spatial planning and urban design; underground planning; infrastructure system planning and environmental impact assessment - solution. The transport planning is a part of infrastructure planning (Figure 1).

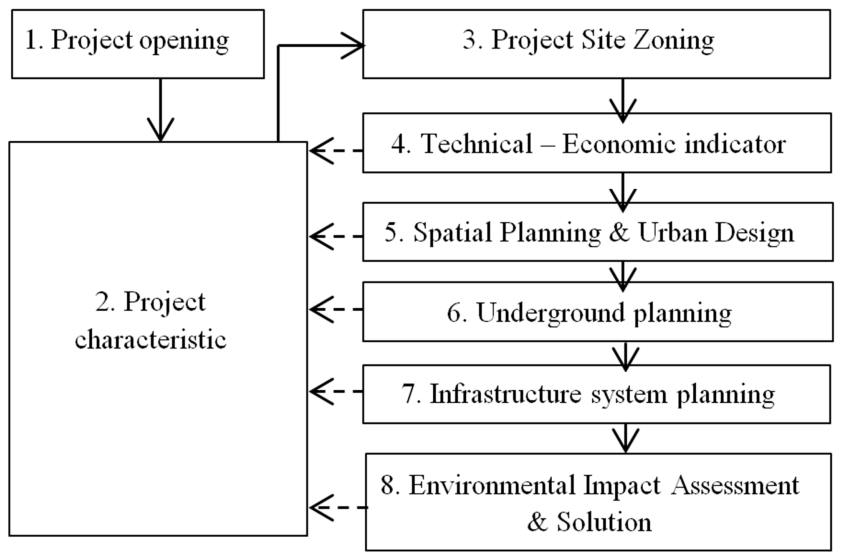

Figure 1. Urban planning process in Vietnam.

\subsection{Opening of Planning Project}

The open part is the first part of the urban planning process which contains some basic information about the project: reason and need for planning project, project targets and objectives, legal framework, and regulations.

\subsection{Project Site Characteristic}

This is a part contains the site information in general, including site location, project boundaries, natural characteristic and current planning situation of project site.

\subsection{Project Site Zoning}

According to the site characteristic, the research site can be divided into zones with different characteristic which lead to the differences in following designs, such as: spatial design urban design, underground structure, infrastructure system, etc. (Figure 2).

\subsection{Technical - Economic Indicator}

This section includes system of technical - economic indicators which are calculated by planners and recommend for future development of the project. Moreover, this section includes land use planning criteria and the structure of construction land fund.

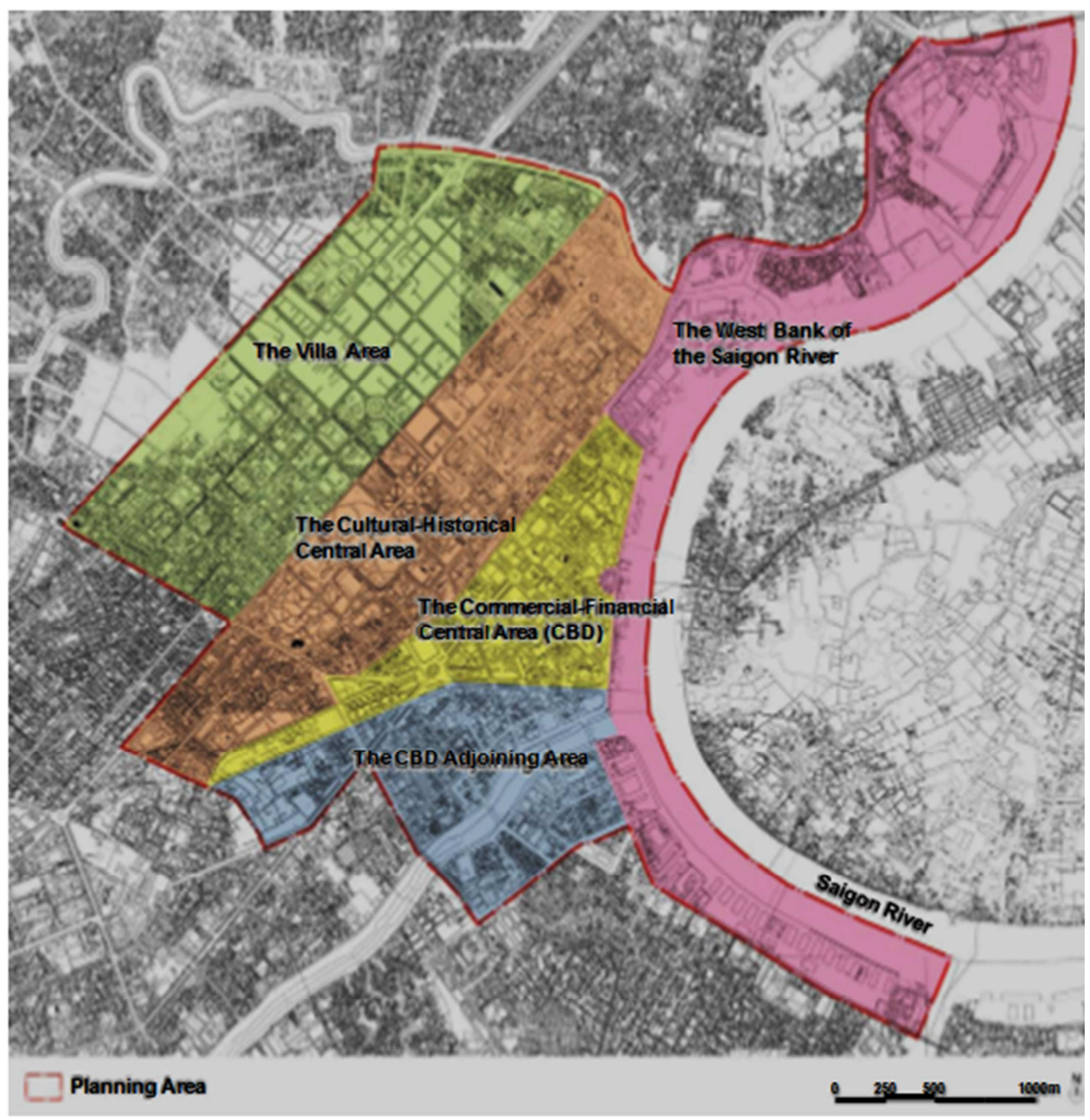

Figure 2. Zoning Map of Detailed Planning of Urban Area 1/2000 (Zoning Plan scale 1/2000). 


\subsection{Spatial Planning - Urban Design}

This is the designing process which includes the urban design principles and its indicators for the whole process and detailed of each zone. Moreover, depend on the scale of the planning project, the planning - architecture indicators can be defined for each specific land plot for future development.

Moreover, this section could include the requirement for construction managing in the project area. In addition, there could be the list of prioritized projects and investment divergence for future development.

\subsection{Underground Planning}

This is the sector that could be planned according to the requirement from the investors.

The underground planning is very important to the overall planning proposal since the underground planning affects the stability of existing buildings and infrastructure system, especially in area with long history of development.

\subsection{Infrastructure System Planning}

Infrastructure system planning is one of the most important processes of the urban planning project, which decides the sustainability of future development in real life. In detailed, most of current problems come from the inappropriate planning of infrastructure system (Figure 3).

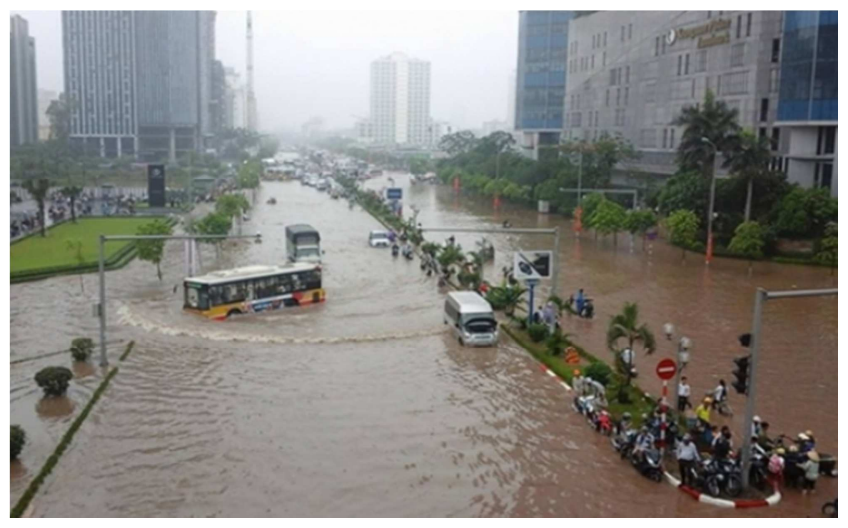

(Sources: Vietnamnet.vn)

Figure 3. Urban Flooding in Ha Noi, Vietnam.

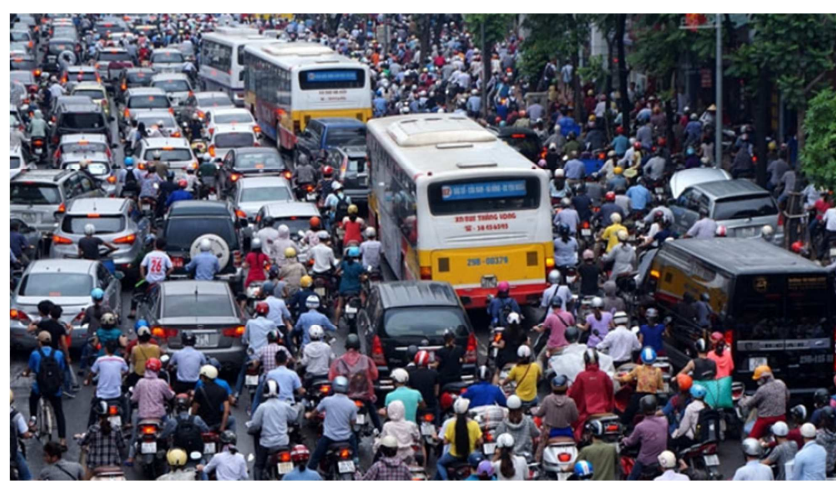

(Sources: Nhandan Online News)

Figure 4. Traffic jam in Ha Noi, Vietnam
Traffic planning is a very important part of infrastructure planning process. The good traffic planning would ensure that people are able travel 'easily' throughout the city for daily activities and improve the effective productivity of society (Figure 4).

\subsection{Environmental Impact Assessment and Solution}

Depend on the scale of planning, the Environment Impact Assessment (EIA) need to be supported by the Strategic Environment Assessment (SEA). In German system, according to German planning legislation (Baugesetzbuch BauGB [2]), the EIA is required for the planning legislation. In Vietnam, the EIA and SEA have been listed in the Law of Environmental Protection 2007, which require the construction project and planning have to practice EIA and SEA in order to get the approve by authorities.

\section{Transport planning Roles and Challenges in Urban Planning Process}

\subsection{Transport Planning Roles}

Due to transport planning important role in the sustainability of future development, traffic planning usually contains about half of contents of the whole infrastructure planning process.

The accuracy of transport planning forecast is the most important part of transport planning process. The planning needs to fulfill the future demand of the development; otherwise, the traffic problems would occur, negatively affect the whole project and wasting resources for improve the situation.

\subsection{Transport Planning Challenges}

In general, the transport planning in Vietnam is conducted based on Transport Impact Assessment (TIA) and the criteria of spatial planning - land use structure - urban design.

The TIA is the planning instrument that forecast the impact of future development to the transport system. In detail, the forecasting process's result is based on combination of the current transport impact evaluation and the future development projects estimation.

In case of Vietnam, the most popular traffic problem is traffic jam, even with the 'professional planning advisory' project, such as: Pham Van Dong Boulevard in Ho Chi Minh City (with 60m width), Nguyen Chi Thanh Street in Ha Noi (called 'the most beautiful street in Vietnam' by Vietnam Ministry of Transport in 2001), Vinholmes Thu Thiem in District 2 of Ho Chi Minh City, etc. The reason for traffic jam is the unexpected increase in traffic demand on the transport system, which was caused by the inappropriate increase of estate development in the short period of time, without or lack of consideration on overall traffic situation. In fact, the accuracy of forecasting the future traffic demand is depend on the input data for TIA and the approach method 
applied in the transport planning process. Therefore, there are 3 main challenges in transport planning:

1. Limitation of TIA application;

2. The limitation in analysis approach method for forecasting and reduction of traffic problem;

3. The lack of communication and synchronous cooperation between departments and other agencies in municipalities.

\subsection{Limitation of TIA Application}

"TIA is the powerful tool for engineers and planners to determine the possible effects of a project on the transportation and traffic system" (Jose Regin et al. [3]) which is very familiar and become the basic requirement of urban planning process around the globe. In fact, TIA concept is still very new in urban manager society, and the TIA application is still very limited. For example: Project Urban area in the West of Ho Tay (Hanoi), the investor only practice the reasonableness assessment of the service network's capacity to adjust the detailed planning and internal traffic organization of the project. Moreover, the Park City project's (Hanoi) investor has intended to implement traffic impact assessment but since this is not required content, it did not been implemented.

Since the TIA concept is still new in Vietnam, the database is still very limited. In fact, there is no official transport planning information system [4]. The traffic information is collected and analyzed individually to serve different objectives by different stakeholders, such as: Ho Chi Minh City Department of Transport and Zalo; Grab; Google, etc. [5]. The lack of input data for analysis has leaded to the low accuracy of TIA result. Therefore, the transport planning cannot fully cover the travel demand in the future.

\subsection{The Limitation in Analysis Approach Method for Forecasting and Reduction of Traffic Problem}

In Vietnam urban planning field, the traffic impact analysis is still a new field with lack of awareness, in term of legal framework. As discuss above, TIA process has not been regulated in the law or legal documents; therefore, the knowledge and analysis tool, related to traffic analysis, has not been fully applied in wide scale area.

Dr. Nguyen Thanh Tu from University of Transport comments "However, until now, there has been almost no formal study that provides a scientific and appropriate process for the actual situation, outlining the necessary procedures and tools to assess the traffic impacts from urban development activities such as construction of industrial and civil works, urban and social infrastructure development, other socio-economic activities of urban areas in Hanoi as well as big cities of our country." on Kien Truc Vietnam Online (Vietnam Architecture Online News) [6]. Even though, the tools for traffic impact analysis, such as: VISUM (for macro traffic simulation) and VISSIM (for tissue) Micro simulation); is being used quite popular in Vietnam, the traffic impact valuation of many projects is not really effective.

Moreover, most of planning map and project are conducted on CAD framework with low quality shaping, especially maps from local government departments, which cause difficulty on transfer data and shaping unit from CAD to other design and analysis framework, such as Geographical Information System (GIS) program. In fact, CAD is a demonstrate tool and does not have the professional analysis function and tool within the program. (Figure 5)

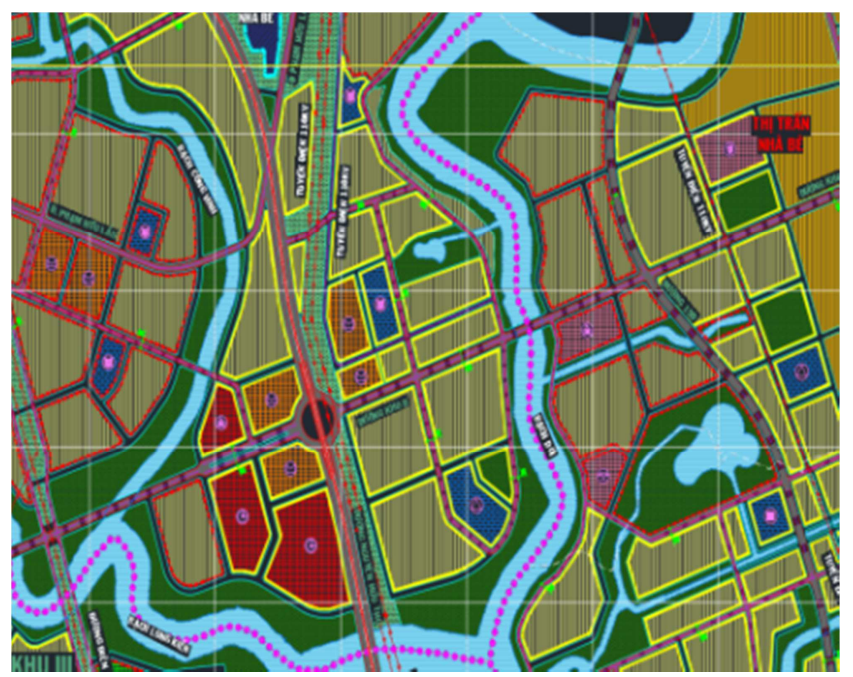

Figure 5. Map of General planning of Nha Be District, Ho Chi Minh City [7]

\subsection{The Lack Communication and Synchronous Cooperation Between Departments and Other Agencies in Municipalities}

In overall, the urban planning is governed by Top - down system, the National government to City's government and local - district government authorities. Therefore, urban planning is governed by several of Ministries and Departments in different level and expertise, depending on level of planning project characteristic [8]. The complicated governance on urban planning has caused the overlapping and difficulty in synchronous cooperation between departments and others agencies [9]. In Vietnam government, every level of authorities, professions and field have its typical type of planning project, conducted by its departments, for example: Transportation has transportation planning, conducted by Ministry of transportation or Department of transportation and 24 districts of Ho Chi Minh City have their own urban planning projects.

On the bright site, since 2017, the national Law on planning [10] has been conducted, contains the combination of different planning aspect of urban planning. This is the most complete legal documents, related to urban planning aspect, regulate the appraisal, decision or approval, publication, implementation, evaluation and adjustment of planning in the national planning system; State management responsibility for planning. This is the signal for signs for efforts from public authorities to improve processes in urban planning. 


\section{Recommendation}

Since Traffic impact assessment (TIA) is a powerful tool for engineers and planners to determine the possible effects of a development project on the transportation and traffic system in both short and long term. Often TIA is applied only to the direct impact area and countermeasures for potential negative impacts are specific for the development in urban area [3]. Therefore, TIA has been applied by many countries for sustainable traffic management and transportation planning in urban areas, such as: Philippines, Malaysia, United States of Americas, etc. In Vietnam, the highest development objective is development toward sustainable development; therefore, TIA application is "must have" requirement for Vietnam urban development in the future. Before the application process, several research on creating scientific framework appropriate to Vietnam urban areas conditions and characteristic. Not only the TIA framework is need but also TIA application and its effect are needed to be evaluated in order to improve and update the quality of previous TIA framework.

Corresponding to the improvement on scientific - technical solutions, the political environment and legal framework have to be updated and modernized. In detailed, the urgent aspect that needs to update first is legal documents on regulating TIA application in all of development project or proposal in order to reach the efficiency transport and traffic system, further to sustainable urban development. Moreover, supportive policies are also needed to encourage individuals and organizations to promote the research on transportation, urban planning and policies development and the creation of National urban planning databased.

A research proposal flow is shown in Figure 6.

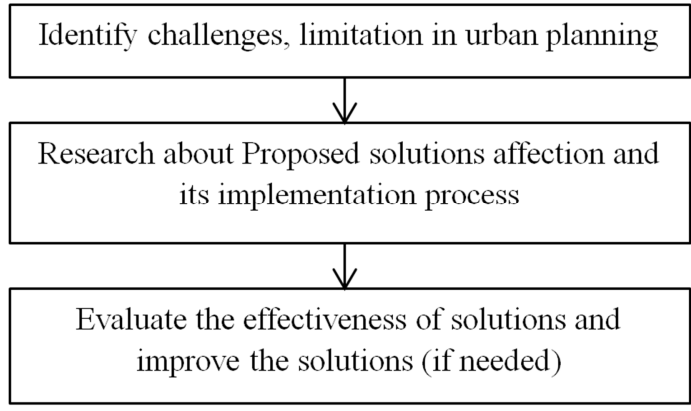

Figure 6. Research proposal flow.

\section{Conclusion}

In conclusion, the Vietnamese transportation planning process in particularly and urban planning in general is incomplete and could not keep up with the development rate of area. Among several difficulties and challenges, there are 3 typical challenges have been pointed out: limitation of TIA application; limitation in analysis approach method for forecasting and reduction of traffic problem; lack of communication and synchronous cooperation between departments and other agencies in municipalities. All of pointed challenges can be linked back to one reason, the slow update of urban planning legal framework which could not keep up with the modern technical and technology development in urban planning field.

In future the research will focus on finding deeper analysis and proposed solution on solving the challenges in term of urban planning in general and transportation planning in particular.

\section{References}

[1] "What is Urban Planning". School of Urban Planning, McGill University. Archived from the original on 8 January 2008.

[2] German planning legislation (Baugesetzbuch - BauGB).

[3] Jose Regin et al., "Traffic impact assessment for sustainable traffic management and transportation planning in urban areas", 2005.

[4] Dinh Thi Thanh Binh, "Impact Assessement - A Decision Making Tool For Urban Development Authority”, 2015.

[5] Saigon Neer, "Saigon Now Have Its Own Traffic Map", January 2017, access link: https://saigoneer.com/saigonnews/9153-saigon-now-has-its-own-traffic-app

[6] Nguyen Thanh Tu, "Assessment of traffic impacts of high-rise buildings in historical inner city", Vietnam Architecture Online News, 2018.

[7] "General urban construction planning readjustment of Nha Be District to 2020", People's Committee of Nha Be District.

[8] "Key Challenges in the Process of Urbanization in Ho Chi Minh City" Workshop, co-convened by The East-West Center Asia-Pacific-U.S. Urban Dialogue and The Ho Chi Minh City Institute for Development Studies in 2009.

[9] "Development Strategies for Ho Chi Minh City's Infrastructure", People's Committee of Ho Chi Minh City, Singapore, 2012.

[10] "Law on Planning", the National Assembly of the S. R. of Viet Nam, (law No. 21/2017/QH14). 